\section{Calculation of the resistance to CSF outflow}

We read the paper by Kahlon et al with great interest. ${ }^{1}$ Comparative studies about the use of different diagnostic techniques to predic the response to shunting in hydrocephalus are of great value as they are likely to form a landmark for future clinical practice. Therefore, it is of paramount importance that the procedures taken for comparison are methodologically sound.

Unfortunately, the interpretation of the lumbar infusion study given by the authors raises our concern. For unknown reasons, the authors have taken into account only the end equilibrium pressure obtained during a constant rate lumbar infusion and neglected the baseline CSF pressure. The authors presumed that this pressure was the same in everybody and equal to the value resulting from the mean taken from the whole cohort $(11 \mathrm{~mm}$ $\mathrm{Hg})$.

Interpretation of the infusion study can be based only partially on the resistance to CSF outflow (Rcsf), with other parameters describing CSF dynamics like the baseline pressure, elasticity, etc, taken into account. ${ }^{2-4}$ The resistance to CSF outflow is, undoubtedly the most important parameter, about which a number of independent studies have been conducted in the past, ${ }^{25}$ including a quite recent multicentre Dutch trial. ${ }^{6}$

The proper way to calculate Rcsf results from the well known Davson's formula:

\section{$I C P_{\text {baseline }}=$ Rcsf $x$ Formation of $C S F+P s s$ (where $P s s$ is sagittal sinus pressure).}

ICP reached during infusion is equal to:

$$
\begin{aligned}
& I C P_{\text {endegitibrium }}=R \operatorname{Rcf} x \text { (Formation of } \mathrm{CSF}+ \\
& \text { Infusion rate) }+P s S
\end{aligned}
$$

Subtracting the first equation from the second it can be derived:

$$
I C P_{\text {endequilibrium }}-I C P_{\text {baseline }}=R c s f \times \operatorname{lnfusion} \text { rate }
$$

From the last equation it seems obvious that the Rcsf must be calculated as the difference between end equilibrium CSF pressure and baseline CSF pressure, divided by the infusion rate (in this case $0.8 \mathrm{ml} / \mathrm{min}$ ).

In cases when the pressure increases above $40 \mathrm{~mm} \mathrm{Hg}$ during infusion, the Rcsf can be presumed to be greater than 40 minus baseline CSF pressure divided by the infusion rate.

There is still not complete agreement about which value Rcsf is normal or pathological (thresholds are ranging from $12 \mathrm{~mm} \mathrm{Hg} /(\mathrm{ml} /$ $\mathrm{min})^{5}$ to $19 \mathrm{~mm} \mathrm{Hg} /(\mathrm{ml} / \mathrm{min}),{ }^{6}$ and are probably age dependent ). Between 13 and 19 $\mathrm{mm} \mathrm{Hg} /(\mathrm{ml} / \mathrm{min})$ there is a "grey zone" in which patients may but they not necessarily should improve after shunting.

Is neglecting the baseline pressure likely to be a meaningful error?

Although the standard deviation of baseline CSF pressure mentioned by the authors is quite low ( $3 \mathrm{~mm} \mathrm{Hg}$ with mean value of 11 $\mathrm{mm} \mathrm{Hg}$ ), this may theoretically mean that some of the patients (although less than 5\%) classified as having normal pressure hydrocephalus may have baseline pressure above 17 $\mathrm{mm} \mathrm{Hg}$ (that is, mean plus twice standard deviation). The "critical threshold" for CSF pressure reached during infusion study should be set for as 28 , not $22 \mathrm{~mm} \mathrm{Hg}$.

We can recall our own material from Cambridge: in 133 adult patients presenting with clinical and radiological symptoms/signs of normal pressure hydrocephalus, constant rate computerised infusion studies were performed. ${ }^{3}$ We calculated properly Rcsf, (that is, taking into account the baseline pressure) and recorded the end equilibrium pressure obtained during the test. The end equilibrium pressure, compared with the threshold calculated as in Kahlon et al ${ }^{1}$ (that is, resulting from the averaged baseline pressure plus $14 \mathrm{~mm}$ $\mathrm{Hg} /(\mathrm{ml} / \mathrm{min})$ multiplied by the infusion rate) was in disagreement with Rcsf below or above $14 \mathrm{~mm} \mathrm{Hg} /(\mathrm{ml} / \mathrm{min})$ in 23 patients. Therefore, by neglecting the baseline CSF pressure as done by Kahlon et al, ${ }^{1}$ we would misjudge 18\% of our tests. It is not huge, but still a meaningful fraction.

M Czosnyka, Z Czosnyka, S Momjian, E Schmidt

Academic Neurosurgical Unit, Addenbrookes Hospital, Cambridge, UK

Correspondence to: $\operatorname{Dr} M$ Czosnyka; mc141@medschl.cam.ac.uk

\section{References}

Kahlon B, Sundbärg G, Rehncrona S Comparison between the lumbar infusion and CSF tap tests to predict outcome after shunt surgery in suspected normal pressure hydrocephalus. I Neurol Neurosurg Psychiatry 2002;73:721-6.

2 Ekstedt J. CSF hydrodynamic studies in man. Normal hydrodynamic variables related to CSF pressure and flow. J Neurol Neurosurg sychiatry 1978:41:345-53.

3 Czosnyka M, Whitehouse $H$, Smielewski $P$, et al. Testing of cerebrospinal compensatory reserve in shunted and non-shunted patients: a guide to interpretation based on observational study. J Neurol Neurosurg Psychiatry $1996: 60: 549-58$

4 Tisell $M$, Edsbagge $M$, Stephensen $H$, et al. Elastance correlates with outcome after endoscopic third ventriculostomy in adults with hydrocephalus caused by primary aqueductal stenosis. Neurosurgery 2002;50:70-6.

5 Borgesen SE, Gjerris F. The predictive value of conductance to outflow of CSF in normal pressure hydrocephalus. Brain

1982; 105:65-86

6 Boon AJ, Tans JT, Delwel EJ, et al. Dutch normal-pressure hydrocephalus study: prediction of outcome after shunting by resistance to outflow of cerebrospinal fluid. J Neurosurg 1997;87:687-93.

\section{Authors' reply}

The comment by Czosnyka and collaborators to Kahlon et al ${ }^{1}$ brings up a highly relevant question concerning the lumbar infusion test in patients with suspected normal pressure hydrocephalus. Namely, if calculations of the resistance to outflow of CSF (Rcsf) is a more adequate measure for predicting the outcome of a CSF shunting procedure than merely recording the steady state CSF pressure level reached during constant rate infusion as originally described by Katzman and Hussey. ${ }^{2}$ Czosnyka et al claim that the latter does not take the initial pressure level (that is, before infusion is started) into account. This is not totally correct. In fact in the equation for calculating Rcsf, the initial pressure level is deducted and only the effect of the fluid volume infused per unit of time is considered. This assumes that the patient's own CSF production is similar before as well as during the infusion of artificial CSF, which may be true but is in fact not known. CSF production may well be influenced (downregulated) by longstanding hydrocephalus.

If the measured initial resting pressure is in the high range, the difference to the infusion steady state plateau pressure level will tend to decrease and if low, the difference will tend to increase. Thus, a high initial resting pressure will tend to disqualify the patient from shunt surgery and vice versa if low. These considerations stimulated us to use the uncorrected infusion steady state pressure level as was originally described ${ }^{2}$ to predict the outcome of shunt surgery.

Several studies have found Rcsf to be a good predictor of outcome of shunt surgery, but almost a similar number of studies have shown a less favourable predictive value (for references, see Boone et $a l^{4}$ ). In two recent studies Rcsf and CSF outflow conductance were calculated in patients with suspected normal pressure hydrocephalus, undergoing shunt surgery based on pure clinical symptoms combined with ventricular widening. ${ }^{4}$ The results were partly divergent and while Malm et als concluded that outflow conductance (reciprocal to Rcsf) had no predictive value, Boone et $a l^{4}$ found that Rcsf could predict outcome of surgery with the best likelihood ratio at a cut off level of about $18 \mathrm{~mm}$ $\mathrm{Hg} / \mathrm{ml} / \mathrm{min}$. In our study the consequence of using Rcsf calculations with cut off levels of 14 or $18 \mathrm{~mm} \mathrm{Hg} / \mathrm{ml} / \mathrm{min}$ had been that $3 \%$ ( 1 of 32 patients) or $22 \%$ ( 7 of 32 ), respectively, of patients with verified improvement after shunt surgery should have been excluded from treatment.

At present we cannot see any obvious reason for not using the steady state infusion plateau level as a simple measure of CSF absorption capacity in clinical practice. From a theoretical basis we can agree to the reasoning by Czosnyka et al, but if calculation of Rcsf in clinical practice is a better predictor than merely recording the steady state plateau pressure level remains to be proved and further data are warranted. We are currently scrutinising lumbar infusion test curves to further elucidate the role of other details than only the plateau pressure for selection of patients likely to be helped by shunt operations.

B Kahlon, G Sundbärg, S Rehncrona The Department of Clinical Neuroscience, Division of Neurosurgery, University in Lund, Sweden

Correspondence to: Dr S Rehncrona; stig.rehncrona@neurokir.lu.se

\section{References}

1 Kahlon B, Sundbärg G, Rehncrona S. Comparison between the lumbar infusion and CSF tap tests to predict outcome after shunt surgery in suspected normal pressure hydrocephalus. I Neurol Neurosurg Psychiatry 2002;73:721-6. 
2 Katzman $\mathbf{R}$, Hussey F. A simple constant-infusion manometric test for measurement of CSF absorption. 1. Rationale and method. Neurology 1970;20:534-44.

3 Silverberg GD, Huhn S, Jaffe RA, et al. Downregulation of cerebrospinal fluid production in patients with chronic hydrocephalus. I Neurosurg 2002:97:1271-5.

4 Boone AJW, Tans JTJ, Delwel EJ, et al. Dutch normal-pressure hydrocephalus study: prediction of outcome after shunting by resistance to outflow of cerebrospinal fluid. J Neurosurg 1997;87:687-93.

5 Malm J, Kristensen B, Karlsson T, et al. The predictive vaue of cerebrospinal fluid dynamic tests in patients with the idiopathic adul hydrocephalus syndrome. Arch Neurol 1995;52:783-9.

\section{BOOK REVIEWS}

\section{Myasthenia gravis and related disorders}

Edited by $\mathrm{H} J$ Kaminski. The Humana Press, Totowa, 2002, US\$125.00, pp 396. ISBN 1 588290581

This is a scientific and clinical review of myasthenia gravis (MG) with chapters on Lambert-Eaton syndrome, congenital myasthenic syndromes, acquired neuromyotonia, and toxin-induced neuromuscular junction disorders. Neuromuscular junction physiology, acetylcholine receptor structure, and immunology are well reviewed in the firs three chapters. The clinical chapters on ocula and generalised myasthenia are uniformly strong, although I have some disagreements. The edrophonium (Tensilon) test can have complications and my preference is to give atropine beforehand. In my experience, few patients with ocular MG (OMG) tolerate ptosis crutches or using adhesive tape. Using steroids "as a last resort" is somewhat extreme: many OMG patients respond well, without side effects, and severe chronic untreated ophthalmoparesis results in fixed deficit which may require strabismus surgery or botulinum toxin treatment. In generalised MG, the use of pyridostigmine, steroids, and azothioprine is discussed. What if these fail? Ciclosporine (bad side effect profile) and mycophenolate are mentioned, but methotrexate is not.

Most readers will not be familiar with the complexity of thymic anatomy and the range of thymectomy procedures. Thymectomy has never been evaluated in a prospective controlled trial but hopefully this will be starting soon subject to funding (Jaretzki has slightly jumped the gun here). This review is excellent.

The chapter on acquired neuromyotonia is handicapped by the lack of clear definition, clinically or neurophysiologically, of neuromyotonia and cramp-fasciculation syndrome. Congenital myasthenia can be very difficult to diagnose and the chapter has an internal contradiction, referring to disorders presenting in infancy and early childhood but then describing adult onset presentations (which are often misdiagnosed). Living muscle microelectrode studies are available in very few centres and clearer clinical guidance would have been helpful. The chapter on toxic neuromuscular disorders (things that bite you or things you should not have eaten) is worth reading.
This book is strongly recommended to clinicians and researchers dealing with neuromuscular disorders (and to thoracic surgeons performing thymectomy).

\section{B Lecky}

\section{Spinal cord medicine, principles and practice}

Edited by D Cardenas, N C Cutter, F Frost, et al. Demos Medical Publishing, New York 2002, US $\$ 225.00$, pp 1085. ISBN 1. $888799-617$

Basically, this is a book about the consequences of severe spinal cord lesions, mainly traumatic injury (spinal cord injury; SCI), and the management of them. It is not a book about spinal cord diseases. So, if you are wondering about the pathogenesis of spinal interneuronitis, or the classification of spinal muscular atrophies, do not look here. But if you spend a significant amount of time involved in the care of patients who are wheelchair dependent as a consequence of SCI or a severe chronic myelopathy such as advanced multiple sclerosis, then the book comes into its own. There are excellent comprehensive chapters about fundamentally important SCI related problems such as respiratory and cardiovascular dysfunction, as well as coverage of more esoteric matters like the immune system and inflammatory response in persons with SCI. Major strengths are found in the multidisciplinary inputs to acute and chronic management and rehabilitation encompassing for instance functional restoration of the upper extremity in tetraplegia, heterotopic ossification, and medical and surgical management of pressure ulcers.

With one editor-in-chief, eight associate editors, and more than 130 authors, repetition and redundancy might be predicted, and unfortunately there is lots of it. For example, no fewer than three chapters cover electroejaculation in varying detail. The author of the foreword writes that the book is a magnum opus. It might be another magnum opus to go through the whole book and sort out the cross referencing, but it needs it. And there is considerable variability. Normal and abnormal micturition is dealt with in just four pages with seven references. The very next chapter, on renal insufficiency in patients with SCI, has 36 pages and 282 references.

This is an American book written for Americans. All of the contributors work in USA or Canada. Poliomyelitis "no longer exists in the US or Canada" so gets no further mention-by those writing the clinical chapter, but no one told the neurophysiologist, who gives polio a whole page (and deals with Kennedy's syndrome too). There is a whole chapter of addresses of useful North American organisations-for example, the telephone company that will install sip and puff dialling. Readers from many countries, perhaps including the UK, will be gobsmacked at the resources available to and spent on SCI patients in the US. At least some countries less blessed than America do not have gunshots as the cause of $17 \%$ of new SCI (41\% in "African Americans").

I welcome this book and trauma centres, SCI units, rehabilitation units, and neurology and neurosurgery libraries will be enriched by it, but the authors need to read each others contributions and adjust their own correspondingly.

R W H Walker

\section{A clinical guide to epileptic syndromes and their treatment}

Edited by C P Panayiotopoulos. Bladon Medical Publishing Limited, Chipping Norton, 2002 , 39.95 , pp 239. ISBN 1-90421823-7

This book is a delightful rarity. It represents the distillation of over 30 years and 100 original publications in clinical epileptology and is a fitting culmination to Tom Panayiotopoulos's distinguished career as an eminent clinical epilepsy specialist. Unashamedly this represents the views of a splitter rather than a lumper when it comes to the classification of syndromes, particularly those affecting children and adolescents. Although the identification of the idiopathic generalised epilepsies, such as juvenile myoclonic epilepsy, has very significant implications for treatment choice and strategy, it remains to be seen to what extent the susceptibility genes that contribute to the common epilepsies mesh with the finer details of the clinical and EEG classification of the epilepsies, and to the design of treatment strategies. In addition to clearly describing the range of epilepsy syndromes and their diagnostic features and management, there are a number of valuable diagnostic and practice tips such as how to recognise infantile spasms.

As occurs all too often, the quality of the content is not matched by the quality of the physical production of this book. This is a 400 page book that is crammed into 278 pages. Margins and borders are cut to the bone, tables and figures are squeezed into too little space and could be better presented. The shortcomings of the physical production are a particular pity because of the good ideas in the formatting of the material, so that particular aspects are easily accessible for those readers who are looking for them: tables of definitions and diagnostic tips are in red figure legends and footnotes are in blue, and the titles of syndromes are in green.

These irritations notwithstanding, I would certainly buy this book to have available for reference when considering the correct classification of a particular patient, and for teaching purposes, and would recommend it to all colleagues who see and treat those with epilepsy, be they studying or working in secondary or tertiary referral practices.

J Duncan

\section{Pediatric psychopharmacology: principles \& practice}

Edited by Andrés Martin, Lawrence Scahill, Dennis S Charney and James F Leckman. Oxford University Press, New York, 2002 £99.50, pp 755. ISBN 0-19-514173-3

This is a weighty text-at nearly 800 pages and nearly $51 / 2 \mathrm{lbs}$ in the hardback edition. Far more than just a textbook of psychopharmacology, this is an introduction to and update on the biological basis of pediatric psychopharmacology as well as its current practice. Organised into four sections, the first covers neurobiology, developmental psychopathology, and genetics, including a well written primer on molecular genetics for those child and adolescent psychiatrists (and there are 
probably many) who have lost contact with their biomedical roots. It was, however, disappointing to see little reference to some of the exciting new imaging studies that are exploring the links between neurobiology and attachment status. Attachment (or affiliation as it is termed here) is covered, but largely in relation to autism and related disorders.

Section two collects together in one place as much information as anyone could want about individual psychotropic agents, but also finds room for chapters on complementary medicine and ECT-strange bedfellows in a subsection on other somatic interventions! The emphasis on placing pharmacological treatments in a developmental context is flagged up in the preface and is a theme that runs through the book. A holistic and integrated approach to assessment and the management of children's problems is advocated clearly throughout.

In the third section, the evidence for treatment of a range of different conditions is reviewed and explained — drug treatments are important but are not the only treatments available. The authors' enthusiasm for the potential value of psychopharmacology is tempered with a clear, evidence based focus, and the different chapters in this section are cautious in their interpretation of the literature and open about the absence of good randomised controlled trial evidence in a number of important conditions. Helpful algorithms support clinical decision making and psychological treatments are recommended, alone or in combination with drug treatments when there is evidence to support this. The MTA study showed the superiority of methylphenidate over treatment as usual even when treatment as usual was usually methylphenidate. One possible explanation was the manner in which the prescribing was carried out in that large multicentre trial, a concept that is supported here with a chapter on the psychology of prescribing.

The book concludes with a section on research and methodological considerations, including interesting chapters on changes in prescribing trends within the US and around the world. Pediatric psychopharmacology is a rapidly growing field with a burgeoning literature. This book, written by clinicians who understand the management of troubled children, brings together that literature in an accessible format. It is up to date and well written. Not perhaps a book for all clinicians to buy, but an essential reference work for any department.

D Cottrell

\section{The Maudsley handbook of practical psychiatry, 4th edition}

Edited by David Goldberg and Robin Murray. Oxford University Press, Oxford, 2002, $£ 19.95$, pp 186. ISBN 0-19-851609-6

This is a pocket sized reference book with a colourful cover that is engaging and forms a good initial rapport. However, after lengthy exposure it did have some difficulties in sustaining my concentration. The writing is clear and unambiguous and there is no flight of ideas or circumstantiality, but the dense writing in a small font makes reading in the poor light of an on-call room difficult.

The mood of the book is objectively difficult to assess ... but my reaction after the evaluation was rather sad. The little use of diagrams, except at the end of the book, and no colour beneath the glossy exterior, makes for a gloomy atmosphere.
However, it is an excellent source of information that is often not readily available, except in larger textbooks. For example, what do you do if someone brings you a gift? What techniques should you use when interviewing children? What are the nuances of cross cultural psychiatry? It does have its drawbacks-trainees need familiarity with ICD-10, but information on this is lacking. There is insufficient guidance about making a diagnosis and psychopharmacology is inadequate, so constant reference to a textbook is necessary.

In summary, it is a book in its 4th edition, which is definitely improving over time, but needs some further follow up.

R Nilforooshan

\section{The neuropsychiatry of epilepsy}

Edited by Michael Trimble and Bettina Schmitz. Cambridge University Press, Cambridge, 2002, £39.95, pp 337. ISBN 0-52181374-3

Various reviews on links between epilepsy and neuropsychiatry are to be found in this book. One of the aims of the editors was to enliven the debate about these links, focusing on their biological and psychosocial mechanisms. The book is divided into sections (eg three chapters on cognitive aspects) and there is excellent cross referencing between different chapters. The editors were right to include a section on non-epileptic attacks, although I was disappointed that all three chapters in this section were almost completely theory based.

There has been no attempt to stamp a housestyle on the various chapters. The reader will find one chapter presenting a thorough disinterested review of the literature, another where the authors have done little more than present their own results, followed by another where the focus is on presenting an explanatory model of symptom formation. Some might criticise this assorted approach, but the result is a book that entertains and educates. Several of the authors are from continental Europe. This perhaps explains why psychodynamic interpretations and treatments are given a high profile. It is fascinating to observe the different approach to neuropsychiatry practised by some of our continental colleagues.

This is not a handbook; practitioners looking for clinical guidance on how to manage their patients will have to carefully select the chapters with a hands on approach. They will find two of the chapters in the treatment sections, written by the editors of the book, on the behavioural consequences of anticonvulsants and the use of psychotropics in epilepsy particularly useful. Other chapters I would select for commendation are on the post-ictal psychoses, dementia and epilepsy, and subtle cognitive effects of epilepsy. All in all a rich collection of papers and a valuable, rather unique book.

S Fleminger

\section{Presumed curable}

By Colin Gale \& Robert Howard. Wrightson Biomedical Publishing Ltd, Petersfield, 2003, $£ 14.50$, pp 128. ISBN 1-871816-48-3

After 38 years as a clinical psychiatrist I still find a good description of a psychiatric patient a revelatory experience because the richness of psychopathology will always exceed the ability of any classification system to condense it into easy categories. What has surprised me is that this fascination does not seem to extend to many of my lay colleagues, even though I have argued with them sometime that the description of mental health problems is much more amusing and interesting than the more popular equivalents such as James Herriot's account of practising as a vet in the Yorkshire Dales. There are several problems in writing about psychiatric patients, two of which are often insuperable to honest publication; the ethical issue of confidentiality - full disclosure is seldom approved and many accounts are bowdlerisedand ambivalence about the way, in descriptions, that patients are perceived. At its worst this ambivalence can be expressed as schadenfreude, the experience of pleasure at other peoples misfortunes, which clearly belittles the experience of mental illness. This book escapes these problems, firstly by writing about patients who were admitted to the Bethlem Hospital in the late Victorian period (although their descendants may be concerned that rather too much is being disclosed) and, secondly, avoided by a frank and objective commentary to what are, in effect, the patients' own stories.

All of them were admitted to Bethlem Hospital between 1880 and 1900 and the title of the book comes from the regulations of the hospital between 1867 and 1906, indicating that "all persons of unsound mind, presumed to be curable" were eligible for admission. What is abundantly clear from this account is that Bethlem was not a Victorian snake pit or workhouse. The high spot of the month was the patient's ball, which was highly regarded by not only those in Bethlem but outside as well. A cartoon appeared in the Punch magazine in 1882 in which a young man of high social standing is boasting to a young lady that he is going to the patient's ball at Bedlam next week. When she expresses concern that he might be detained he responds "don't worry, they only take in the curable cases". However, the accounts of the 60 patients in this book, each with their own photograph (several taken by that polymath Francis Galton in his eugenics phase), indicate that a large proportion were "discharged uncured" to private or public asylums. Each account included a description of form of admission, often with quotations from relevant doctors' letters, and a brief summary of the outcome. In between there is a great deal that describes the patients' own experiences and feelings. All these have been set forth extremely sensitively by the editors and I consider the outcome to be an outstanding piece of mini-biography, which encapsulates the essence of (largely) people with psychosis, with little or no insight, angrily but ineffectually taking on people whom they considered to be their oppressors. Thus, we read of William Chark, attempting to obtain his discharge by refonning the Lunacy Act, of Walter who complained fonnally to the position superintendents that "you have systematically and fraudulently ruined my social and commercial position" but was still able to "forget himself at dances and noticed to be taking ladies round the waist with both hands", and William who took a particular dislike to Dr Savage, Bethlem's Physician Superintendent (later be one of Virginia Woolf's medical attendants, and therefore mercilessly dissected in her writings), by writing a poem to him which remained in his case notes, it illustrates that although our Victorian patients may have been ignored more than their 
equivalents today they were still just as vocal, and at times it is hard to believe that we are not reading about today's patients.

This book is a great read for all involved in mental healthcare. It makes us aware of the enmity we engender whenever we use our powers of detention. Part of William's ode to Dr Savage is an apt reminder:

"Dear Doctor,

When the trumpet sounds,

And God proclaims the judgement day,

You'll try I know to be at least,

Some 50 miles or more away,

'Twill be of no use no tree no bush,

Will hide you from God's searching eye,

With other savages you'll have

To toddle up your luck to try".

And Virginia was yet to come.

\section{Neurosurgery of arteriovenous malformations and fistulas. A multimodal approach}

Edited by Hans-Jakob Steiger, Robert SchmidElsaesser, Alexander Muacevic, Hartmut Bruckmann, and Berndt Wowra. Springer, New York, 2002, £228, pp 473. ISBN 3-2-1 1-83703-5

This is an interesting text aimed solely at arteriovenous malformations but including the often forgotten arteriovenous fistulas. The authors consist of the Neurovascular Surgical Team at the Ludwig-Maximilians-Universität, Munich, in conjunction with the Chairman of Neuroradiology at the same institution and the Director of the Gamma Knife Centre in Munich. The spectrum of authors covers the multimodal approach described in the title of the book. The aim of the book is therefore to appeal to specialists of surgical, radiosurgical, and endovascular disciplines. Its aim is to highlight the evolution of treatment of arteriovenous malformations and arteriovenous fistulas since the first neurosurgical efforts to deal with occluding and excising these lesions. It illustrates the growth in what were initially adjuvant treatments, but are now part of a multimodal combination of treatments. I think the book does this very well. It begins by reiterating the basics with a literature review covering definitions, epidemiology, and clinical characteristics, as well as treatment options of AVMs and fistulas of the CNS, including brain and spine.

It also considers the classification systems based on theory and the pathoanatomical relationship between morbid intervention and thus choice of treatment. It then goes on to discuss the result of the various modalities of surgery, embolisation, and radiosurgery in a detailed literature review. This is followed by an in depth analysis of the principles of surgery, endovascular, and gamma knife options. The relative risks and merits of each are compared. Finally, in true keeping with its clinical perspective, the book concludes with a number of case studies illustrating the combination of both surgical and endovascular approaches as well as exclusively endovascular, exclusively surgical, and finally major surgical cases.

I found the book was well structured and illustrated, making for an easy and informative read. It would be a very welcome addition to the library of any neurovascular unit and it would be of interest to all the disciplines involved in treating these abnormalities.

K O’Neill

\section{HIV neurology}

B J Brew. Oxford University Press, New York, 2001, £75.00, pp 252. ISBN 0-19513363-3

Do we need books anymore? I found myself asking this rather shocking question when an exceptionally keen medical student brought a series of current reviews relating to a patient we had seen in clinic together, downloaded from the internet within minutes of the clinic ending. HIV neurology provides at least one rationale for book publishing. Given the epidemiology of HIV in the UK, most neurologists will encounter HIV associated neurological problems rarely. Most of the physicians who look after patients with HIV disease are familiar with common neurological problems. Neurologists will therefore tend to find themselves either considering HIV associated disease as part of the differential diagnosis in patients whose HIV status is not known, or being asked for opinions once more straightforward HIV complications have been considered. This book seems to have been designed with this in mind and is organised to allow ease of reference.

The first section provides an overview of HIV disease with a succinct and accessible summary of the virology, with an outline of general treatment. The approach to neurological diagnosis is explored including useful concepts to help neurologists abandon Occam's razor, as they must in HIV disease. These include "time locking", the linking of the potential complication to the stage of HIV infection; "parallel tracking", the recognition that multiple levels of the nervous system can be involved in the same disease process to confuse the clinical presentation; and "layering", the idea that multiple pathologies can affect the same level of the nervous system. The subsequent sections are based on the levels of the nervous system affected: predominantly non-focal complications relating to the brain; focal complications; spinal cord; peripheral nerve; and finally muscle. Each section discusses the many complications on conventional lines, epidemiology, clinical features, investigations, neuropathology, pathogenesis, and treatment. These are well referenced and throughout there is strong feeling that they have been written by someone with an extensive practical experience of the clinical problems described.

Reading the book in the usual way I did find some repetition, but this is an unfair criticism as the book is intended for reference section by section. There is also an assumption that somehow all neurological symptoms suffered by patients with HIV are in some way related to HIV and that they are immune to more conventional problems. The section on "HIV headache", a commonly occurring throbbing headache for which no cause is found and which anecdotally responds to amitriptyline, which in other clinics seems familiar enough, perhaps best illustrates this.

These minor gripes aside I think this is a useful book, although expensive at $£ 75$. It is much more than the sum of the references within it as it brings a thoughtful integration of the clinical approach to patients with HIV neurology. For most neurologists this book will beat the internet.

G Fuller

\section{Ageing and dementia. Current and future concepts}

Edited by KA Jellinger, $R$ Schmidt and $M$ Windisch. Springer Wien New York, Wien, 2002, €108 000, pp 376. ISBN 3-211 83797-3

This contribution represents a summary of an international symposium on "ageing and dementia", which took place in Vienna at the end of September 2001. The preface states that as a result of the aftermath of 11 September 2001, the hitherto internationally renowned invited speakers had to be reorganised within a short time. Three key issues were addressed in the meeting-factors that contribute to brain ageing, detection of mild cognitive impairment, and preventive and therapeutic methods that alter these effects. The result is 376 pages comprising 33 contributions over a range of subjects and covering a wide array of approaches from basic science to clinical matters. The authors represent a wide span of interests and countries (although I guess the first author of the publication was not necessarily always the presenting author at the symposium).

The concept of vascular dementia is summarised very well by the senior editor, and a discussion of the relevance of vascular changes and their rating on brain scans follows. Some discussion on basic process in the genesis of Alzheimer's disease is intermingled with a contribution discussing a specific marker, followed by discussions of treatment approaches in Alzheimer's disease and mild cognitive impairment.

The volume is something of a mixed bag, with a very useful overview written by leaders in the field, coupled with detailed experimental results. They represent, presumably, a faithful summary of the presentations at this particular symposium, but lack something of a thread with which to draw the contributions together. A degree of organisation with perhaps a brief introduction to particular subjects would have been helpful and easily achieved, with reference to the organisers' aspirational themes. Some of the contributions are lengthy, while others are rather curt.

That being said, because of its wide approach, it will have wide appeal, and one can safely say that there is something for everybody within its covers. The editors and contributors have succeeded in producing a volume that is of relevance and a pleasure to read. One cannot underestimate the difficulties the organisers had in sustaining the impetus to continue with the meeting after the terrifying events of the 11th September, and this compendium, perhaps, is a piece of evidence to show that things can and should continue as usual.

A Burns 
HISTORICAL NOTE

\section{The nucleus of Theodor Meynert (1833-1892)}

n 1664 Thomas Willis described distinct subcortical structures, then called the corpus striatum. It was believed to be the "sensorium commune" as defined by Aristotle; a central structure that received sensory modalities and initiated motor acts. By 1914, Wilson wrote that the corpus striatum "seemed to fall from its high estate and depreciate in physiological significance". It gained importance with the discoveries that lesions of these areas would result in abnormal motor functions. The corpus striatum came to be viewed as the major "extrapyramidal motor system".

Meynert developed new techniques and used thin serial sections stained with carmine or gold with quantitative neurohistological measurements. His major aim was to relate cortical function to varied cell types and to establish the neural association fibres (radiations of Meynert) ${ }^{1}$ within the brain. This predated the work of Fritsch and Hitzig in 1870.

He thereby produced the first description of the lamination and cellular diversity of the cerebral cortex in Stricker's Handbook of human and animal histology (1872). In section three he describes a clearly extended ganglion underneath the fibres of the ansa peduncularis as the second layer of substantia innominata, named "Ganglion der Hirnschenkelschlinge". Its large spindle like hyperchromatic nerve cells were measured. Because of this new element in the substantia innominata, Meynert distinguished four parts of the area: ansa peduncularis; nucleus (ganglion) of the ansa peduncularis; inferior (ventral) peduncle of the thalamus; and anterior part of the stratum zonale thalami.

Meynert's powers of description were not the most lucid, and in 1896 Albert Köelliker renamed the ansa ganglion "Meynert's basal ganglion":

"The central, nearly superficial part of the disc-like formation of Meynert's basal nucleus is found in the basal forebrain parallel to the ventral basis of the Nucleus lenticularis and underneath the Commissura anterior from its lateral entrance onwards; laterally, it reaches the Amygdaloid complex; caudally it extends towards the Tractus opticus; its oral part makes contact with Substantia perforata anterior, the medial one reaches the Tuber cinereum."

Meynert ${ }^{2-3}$ was born in Dresden on 14 June 1833. His father was a historian, his mother an opera singer. When he was eight, the family moved to Vienna and the influence of artistic and bohemian living never quite left him.

As a student, he worked with Wedl and Rokitansky, who fostered his talents. He received his medical doctorate after an untamed student life, in 1861. On the basis of his thesis Structure and function of the brain and spinal cord and their significance in disease, he was appointed "Privatdo-zent" in 1865 and Director of the Prosectorium of the state psychiatric hospital in Vienna. Regarded as prophet of scientific progress, he rapidly published several pioneering discoveries. ${ }^{4}$ In 1873 he became professor of nervous diseases. Meynert's novel ideas drew many visitors to Vienna, but he was considered a poor teacher. His department, Forel related, was disorderly and filthy.

He was a small melancholic man with a massive head, a sprawling bushy beard, and mane-like hair. With colleagues he was brusque and, at times, dismissive, but his son had died aged 17, his wife also died young. His admirable drawings of the brain remain in the Neurological Institute of Vienna. His concepts of the brain ${ }^{5-6}$ he obscurely summarised:

"The main function of the central organ is to transmit the fact of existence to an ego gradually shaping itself in the stream of the brain ... If we look upon the cortex as an organ functioning as a whole then the information that it subserves the processes of the mind is all that can be said . . .To think further about the cortex is impossible and unnecessary . . .But our hope to understand eventually the function of the hemispheres is raised again by the opposite assumption which leads us straight to an organology of the central surface . . Between these two theoretical possibilities the facts have to decide."

He studied minutely the visual, hippocampal cortex, the olfactory lobe, and septum pellucidum. He separated the cortex with white surface (allocortex) from the cortex with a grey surface (neocortex) and created the phrase "organology of the cortex", reflecting the function of brain as an organ. Central integration was dependent on the association process. He considered the motor cortex and basal nuclei as functionally antagonistic; thus, disease would lead to extrapyramidal disorder. He went on to point out the sensory feedback from muscles to the cortex. These and other highly original ideas were published in his Klinische vorlesungen uber psychiatrie auf wissen schaflichen grundlagen, in 1890.

Meynert was editor of the Wiener Jahrbücher für Psychiatrie and co-publisher of the Archiv für Psychiatrie und Nervenkrankheiten (Berlin) and of Vierteljahrsschrift für Psychiatrie. He was President of the Wiener Verein für Psychiatrie und Forensische Psychologie.

He inspired the work of Paul Emil Flechsig (1847-1929), Karl Wernicke (1848-1905) and Auguste-Henri Forel (1848-1931), Putnam, Bernard Sachs, and Sigmund Freud (1856-1939).

In 1870 he was appointed Director of the Psychiatric Clinic and he started a neurological outpatient clinic in 1887. In later years he enjoyed high civic honours. However, he suffered grave personal losses in his family and untimely died at Klosterburg on 31 May 1892.

James Papez lists many of his main publications and biographies. ${ }^{4}$

J M S Pearce 304 Beverley Road, Anlaby Hull HU10 7BG, UK

References email: jmspearce@freenet.co.uk

1 Clarke E, O'Malley CD. The human brain and spinal cord: a historical study. 2nd ed. San Francisco: Norman, 1996:432-7. 602-3

2 Mayer C. Obituary in Wiener klinische Wochenschrift, 1933;46:738-41.

3 Jolly F. "Theodor Meynert". Arch Psychiat Nervenkr 1892;24:3-7.

4 Papez JW. The founders of neurology, 2nd ed. In: Haymaker W, Schiller F, eds. Springfield, Charles C Thomas, 1970, 57-62.

5 Meynert TH. Der bau der gross-hirnrinde und seine örtlichen verschiedenheiten nebst einem pathologisch-anatomischen. Corollarium. Vierteljahrsschrift für Psychiatrie, Neuwied and Leipzig 1867;1:77-93, 198-217; Vierteljahrsschrift für Psychiatrie, Neuwied and Leipzig 1868,2:88-113.

6 Meynert TH. Psychiatrie klinik der erkrankungen des vorderhirns. Wien, W. Braumüller, 1884. 